\title{
Development in Lithium/Sulfur Secondary Batteries
}

\author{
Yongguang Zhang, Yan Zhao, Kyung Eun Sun and P. Chen* \\ Department of Chemical Engineering, University of Waterloo, 200 University Avenue West, Waterloo, Ontario, N2L \\ $3 G 1$, Canada
}

\begin{abstract}
This paper reviews different modification methods to cathode, anode and electrolyte materials in view of their electrochemical properties for application in lithium/sulfur batteries. In the sulfur electrode, carbonaceous materials, conductive polymer materials, and metal oxide adsorbing materials are employed to enhance conductivity and reduce polysulfide dissolution. The effects of anodes and novel electrolytes, such as gel polymer, solid polymer and solid ceramic electrolytes, are reviewed.
\end{abstract}

Keywords: Lithium sulfur battery, cathode, modification, polysulfide dissolution.

\section{INTRODUCTION}

\subsection{General Introduction of Lithium Sulfur Batteries}

The lithium-ion rechargeable batteries have been widely used in the portable electronic devices such as laptops, cameras and cell phones [1-4]. The rapid growth of electric vehicles has been requiring the development of next generation batteries with high specific capacity and energy density. Lithium/Sulfur $(\mathrm{Li} / \mathrm{S})$ cell is one of the most promising candidates for a storage device due to:

(1) Low cost and abundant resources of sulfur;

(2) Non-poisonous and environment friendly;

(3) Wide temperature range of operation;

(4) Intrinsic protection mechanism from over charge, providing safety;

(5) Possibility of long cycling [5].

Furthermore, the $\mathrm{Li} / \mathrm{S}$ battery yields a high theoretical specific capacity of $1675 \mathrm{mAh} \cdot \mathrm{g}^{-1}$ and theoretical specific energy of $2500 \mathrm{Wh} / \mathrm{kg}$ (or $2800 \mathrm{Wh} / \mathrm{L}$ ) on a weight or volume basis respectively [6], based on the $\mathrm{Li} / \mathrm{S}$ redox couple, $\mathrm{S}+2 \mathrm{Li}^{+}+2 \mathrm{e}^{-} \leftrightarrow \mathrm{Li}_{2} \mathrm{~S}$ on the assumption of the complete reaction of lithium with sulfur to $\mathrm{Li}_{2} \mathrm{~S}$. It differs from conventional lithium batteries For example, the specific capacities of $\mathrm{LiMn}_{2} \mathrm{O}_{4}, \mathrm{LiCoO}_{2}$ and $\mathrm{LiNiO}_{2}$ are 126, 149 and $180 \mathrm{mAh} \cdot \mathrm{g}^{-1}$, respectively [7], whose values are limited by the extent of lithium intercalation into transition metal oxides [8] - reversible uptake of $\mathrm{Li}$ ions and electrons in a solid with minimal change to the structure. Typically, a lithium transition-metal oxide or phosphate is used as a positive electrode that re-intercalates $\mathrm{Li}^{+}$at a high potential with respect to the carbon negative electrode [9].

The high capacity and recharge ability of sulfur can be achieved from the electrochemical cleavage and reformation of a sulfur-sulfur bond in cathode [9].

*Address correspondence to this author at the Department of Chemical Engineering, University of Waterloo, 200 University Avenue West, Waterloo, Ontario, N2L 3G1, Canada; Tel: (519) 888-4567x35586; Fax: (519) 746-4979; E-mail: p4chen@uwaterloo.ca

\subsection{Problems and Shortcoming about Lithium Sulfur Batteries}

The discharge process of the Li/S battery proceeds in two steps [10]: first, the transformation of sulfur to lithium polysulfide $\left(\mathrm{Li}_{2} \mathrm{~S}_{\mathrm{n}}, \quad 2<\mathrm{n}<8\right)$ and followed by the transformation of lithium polysulfide to lithium sulphide $\left(\mathrm{Li}_{2} \mathrm{~S}\right)$ [11-13]. The lithium polysulfide, which is formed during the first discharge step of $\mathrm{Li} / \mathrm{S}$ battery, is dissolved into the electrolyte, which causes the irreversible loss of the sulfur active material [13-18].

According to Nimon and co-workers [19], when polysulfide was dissolved into an electrolyte, it was also diffused into the lithium anode and reacted with the lithium to reduce the cycling efficiency. Thus, the cyclic behaviour of the $\mathrm{Li} / \mathrm{S}$ battery becomes very poor mainly due to the polysulfide dissolution into the electrolyte.

In the present paper, we introduce different methods to modify the cathode, electrolyte and anode materials to overcome the problem of polysulfide dissolution into electrolyte.

\section{EFFECT OF CATHODE AND MODIFICATION}

\subsection{New Preparation Methods on Cathode and Modification on Polysulfide Dissolution}

The disappointing result from electrochemical reaction caused by the polysulfide could be improved by trapping the polysulfide inside of the cathode with the help of carbonaceous materials, the components in the sulfur cathode.

Carbon particles in the carbon-sulfur composites have a strong adsorption of the polysulfide to additive materials, which have a large surface area and a high porous structure.

In Wang et al.'s research [20], the cathode material composites were prepared with a structure of elemental sulfur embedded and trapped in nano-pores and micro-pores of active carbon to overcome the loss of the active mass in the cathode, which showed good cycle ability in rechargeable lithium cell based on gel electrolyte. The 
reversible capacity of the composite was about $440 \mathrm{mAh} \cdot \mathrm{g}^{-1}$ and the utilization of sulfur during cycling approached $90 \%$.

Mesoporous carbon was reported [21] that it is used in industry as an adsorbing material because of their high surface area. Furthermore, mesoporous carbon has good electrical conductivity.

According to Liang et al. [22], a soft-template synthesis method is applied to produce sulfur/caron composite cathode for $\mathrm{Li} / \mathrm{S}$ rechargeable batteries. This method is first introduced by Liang ${ }^{[23-26]}$ to synthesize mesoporous carbon. After activating mesoporous carbon using potassium hydroxide $(\mathrm{KOH})$, the carbon obtains a hierarchical structure with a bimodal pore size (micropore and mesopore). The bimodal pores play important roles during electrochemical reaction: micropores trap sulfur particles to give high electrical conductivity and to prevent the particles from escaping from cathode; and macropores allow a large number of lithium ions to transport between anode and cathode, which leads to high ionic conductivity. As a result, initial discharge capacity reached $1584 \mathrm{mAh} \cdot \mathrm{g}^{-1}$; this value is greater than the literature value of $1155 \mathrm{mAh} \cdot \mathrm{g}^{-1}$.

Wang et al. [27] reported that sulfur-mesoporous carbon composite $(\mathrm{S} / \mathrm{C})$ was prepared by heating a mixture of elemental sulfur and synthesized mesoporous carbon. A novel electrolyte was prepared by dissolving lithium bistrifluoromethane-sulfonimidate (LiTFSI) in the synthesized ionic liquid consisting of 1-ethyl-3methylimidazo-lium bis(trifluoromethylsulfonyl)imide (EMITFSI) at a concentration of $1 \mathrm{~mol} / \mathrm{L}$. The $\mathrm{S} / \mathrm{C}$ composite was tested in both the ionic liquid and the organic solvent electrolytes. And the $\mathrm{S} / \mathrm{C}$ composites using ionic liquid electrolyte showed better results in the capacity and cyclic stability than that of the conventional organic solvent electrolyte of $1 \mathrm{~mol} / \mathrm{L}$ LiTFSI-PEGDME.

CMK-3, the most well-known member of the mesoporous carbon family, was studied as CMK-3/sulfur composite in the Li/S battery [9]. It was found that the sulfur was homogeneously distributed in the framework of the mesoporous carbon, which allows ingress of electrolyte within the structure. The empty volume within the pores is also available to accommodate the uptake of $\mathrm{Li}$ ions, due to the lower density of $\mathrm{Li}_{2} \mathrm{~S}$ compared to the sulfur. The insulating sulfur only occupied the empty channels in the mesoporous carbon and does not block the electrical current transporting paths [9].

To reduce the dissolution of the polysulfide into the electrolyte, the polymer, polyethylene glycol (PEG) chains of varying molecular weight, was coated on the external surface of the composite (CMK-3/S), further helped retard diffusion of polysulfide out of the cathode structure. It was found that the cycling stability was improved. The initial discharge capacity was increased to $1320 \mathrm{mAh} \cdot \mathrm{g}^{-1}$, but no fading was observed in the second 10 cycles and the capacity was stabilized at $1100 \mathrm{mAh} \cdot \mathrm{g}^{-1}$ on cycling.

Wang et al. studied Polyacrylonitrile(PAN) [28] as the reaction precursor with elemental sulfur heating at 280$300^{\circ} \mathrm{C}$ to obtain a novel conductive sulfur containing material. The composite, with sulfur embedded in this conductive polymer matrix, which was expected to hinder the sulfur and polysulfide from dissolving into the electrolyte, improved the electrochemical kinetics of the sulfur cathode. The lithium battery with PAN/sulfur composites as the cathode active material has high capacity density and good recharge ability. The specific capacity of the composite was up to $850 \mathrm{mAh} \cdot \mathrm{g}^{-1}$ at the first cycle. The specific capacity remained above $600 \mathrm{mAh} \cdot \mathrm{g}^{-1}$ after 50 cycles, which demonstrated high sulfur utilization and relatively stable cycle behaviour.

PAN, however, shows poor electrical conductivity in the cathode, which limits the high power rate of sulfur composite materials. To solve this problem, further study [29] was done by using the carbon nanotubes (MWCNTs) to set up a highly conductive network in the composite, PAN/sulfur cathode. It was found that MWCNTs not only kept the cathode integrity and accommodated the volume change during charge/discharge processes, but also provided stable channels for electrical and ionic conduction at high power rates. By applying MWCNTs, sulfur utilization and cycling stability of the cathode had been significantly improved. The capacity remained $96.5 \%$ of sulfur utilization after 100 cycles. Moreover, the PAN/sulfur composite exhibited excellent high power rate capability up to $7 \mathrm{C}$ (386.7 $\left.\mathrm{mAh} \cdot \mathrm{g}^{-1}\right)$.

Zhang et al. [30] introduced a novel polymer, polyaniline polysulfide (SPAn), which can hold more sulfur in the polymer than the others. The polymer has polyanilline as the backbone chain and 2 four-member rings with S-S bonds as the side chains of aniline. From the structure, it is predicted that the polymer can store high energy when it is used in $\mathrm{Li} / \mathrm{S}$ battery. The result of Li/S battery with SPAn showed high initial discharge capacity of $980 \mathrm{mAh} \cdot \mathrm{g}^{-1}$ and a stable reversible capacity of $403 \mathrm{mAh} \cdot \mathrm{g}^{-1}$ after 20 cycles.

In the other research group, Ma et al. [31] developed polyaniline/sulfur composite cathode, which was synthesized by situ polymerization. The aniline was polymerized to form a layer of polyaniline on the sulfur surface. The results showed that the composites reached $1134.0 \mathrm{mAh} \cdot \mathrm{g}^{-1}$ at the first cycle, which is relatively low compared to the results from the other polymers containing sulfur. The capacity remained $526.9 \mathrm{mAh} \cdot \mathrm{g}^{-1}$ after 30 cycles.

In Song et al.'s research [10], nano-sized $\mathrm{Mg}_{0.6} \mathrm{Ni}_{0.4} \mathrm{O}$ synthesized by the sol-gel method was used as an additive, which has the polysulfide adsorbing effect. It was explained that the crystal structure of $\mathrm{Mg}_{0.6} \mathrm{Ni}_{0.4} \mathrm{O}$ is the same as $\mathrm{MgO}$, which has the effect of retaining liquid electrolyte in a Li/iron sulphide secondary battery like an electrolyte sponge [32].

Furthermore, $\mathrm{Mg}_{0.6} \mathrm{Ni}_{0.4} \mathrm{O}$ has a catalytic effect of dissociating the chemical bond, which was expected to apply to the $\mathrm{Li} / \mathrm{S}$ battery considering the dissociation energy of the $\mathrm{S}-\mathrm{S}$ single bond [32]. As the result, it was found that the capacity and cyclic ability of the $\mathrm{Li} / \mathrm{S}$ battery at room temperature were improved, when $\mathrm{Mg}_{0.6} \mathrm{Ni}_{0.4} \mathrm{O}$ was used as an additive in sulfur cathode.

Zhang et al. [1] reported a novel cathode material created with $\mathrm{V}_{2} \mathrm{O}_{5}$ and sulfur for $\mathrm{Li} / \mathrm{S}$ rechargeable batteries to improve electrochemical performance. The cathode material was prepared via the sol-gel method. The initial discharge capacity was $473 \mathrm{mAh} \cdot \mathrm{g}^{-1}$. This value is less than that of the sulfur cathode battery, whose initial discharge capacity was 
$535 \mathrm{mAh} \cdot \mathrm{g}^{-1}$, due to the low specific capacity of $\mathrm{V}_{2} \mathrm{O}_{5}$. However, the result showed that capacity and the rate capacity were increased and the utilization of active material was improved.

This research group [33] further studied the effect of $\mathrm{Mg}_{0.8} \mathrm{Cu}_{0.2} \mathrm{O}$ addition into the $\mathrm{c}-\mathrm{V}_{2} \mathrm{O}_{5} / \mathrm{S}$ composite cathode was investigated on the electrochemical performance of $\mathrm{Li} / \mathrm{S}$ rechargeable batteries. As the result, the cyclic ability and discharge capacity were improved after the addition of $\mathrm{Mg}_{0.8} \mathrm{Cu}_{0.2} \mathrm{O}$. The initial discharge capacities of the cathode with and without additive were 545 and $400 \mathrm{mAh} \cdot \mathrm{g}^{-1}$ respectively, which showed that not only did $\mathrm{Mg}_{0.8} \mathrm{Cu}_{0.2} \mathrm{O}$ has the adsorbing effect on polysulfide, but also a catalytic effect on promoting redox reaction of the $\mathrm{Li} / \mathrm{S}$ batteries.

\subsection{Modification on Conductivity of Cathode}

To improve the electrochemical results, it is important to retain the polysulfide in the cathode to prevent it from being involved in the redox reaction, which occurs at the surface of the carbon. To do so, the morphology of the carbon matrix must be controlled that it can easily accept the polysulfide, such as uniformity of the carbon matrix and the structural stability [34].

Choi et al. [35] presented that carbon nano-fiber (CNF) with an average diameter of $150 \mathrm{~nm}$ was added into the cathode to improve cyclic ability. Cathode, with CNF using $\mathrm{PEO}$ and $\mathrm{PVdF}$ as the binders, showed better cycle property than the one without CNF. As the result, cyclic ability was improved when CNF was added to the cathode because CNF provides a good electrical connection and a structural stability. The cycling life (up to $60^{\text {th }}$ cycle) of SPEAC was more stable than that of CNF because of the suppression of agglomeration of sulfur or lithium sulphide by the addition of CNF.

In Han's research [34], multi-walled carbon nano-tubes (MWCNT), prepared by thermal chemical vapour deposition, were used as an inactive additive material for elemental sulfur cathodes for $\mathrm{Li} / \mathrm{S}$ rechargeable batteries. MWCNT, as a conductive agent in the cathode, was used to increase the retention of soluble polysulfide on cathode and to increase the stability of the carbon matrix, which could provide the increase of both sulfur utilization and cyclic ability of the sulfur batteries. It was explained that the assembly of the relatively long and thin carbon nano-tubes can generate three dimensional network structures with regular pores, which helped retention of the polysulfide in the cathodes. The sulfur/MWCNTs electrode retained high specific capacity at high discharge rate due to an electronically conducting network developed from the MWNTs which are more effective than that of acetylene black.

For the past decades, researchers have been developing novel conductive polymer-sulfur cathode materials has a potential to be one of the active components for the $\mathrm{Li} / \mathrm{S}$ rechargeable batteries. The addition of the polymer to the sulfur cathode increases the conductivity and stability; therefore, good cyclic ability was obtained.

Conductive polypyrrole (PPy) coating on the surface of the sulfur powder improved the conductivity of S-PPy electrode. Furthermore, PPy could also act as a binder, increasing the contact between particles.

Sulfur-polypyrrole(S-PPy) was synthesized via chemical polymerization using sodium ptoluenesulphonate as the dopant, 4-styrenesulphonic sodium salt as the surfactant, and $\mathrm{FeCl}_{3}(0.1 \mathrm{M})$ as the oxidant [36]. PPy nanoparticles coated on the surface of sulfur powder may have trapped the highly polar polysulfide species. As a result, the composite showed good electrochemical properties, improvement of cyclic ability of the cell and increment of the initial discharge capacity from 1100 to $1280 \mathrm{mAh} \cdot \mathrm{g}^{-1}$ after coating with the polypyrrole.

Wire-, ribbon-, and sphere-like nanostructures of polypyrrole have been synthesized by solution chemistry methods in the presence of various surfactants (anionic, cationic, or nonionic surfactant) with various oxidizing agents [ammonium persulfate (APS) or ferric chloride $\left(\mathrm{FeCl}_{3}\right)$, respectively [37].

By using cationic surfactants as soft templates, a novel nanowire of sulfur-polypyrrole positive electrode is prepared via simple heating method [38]. The result of the electrochemical performance of $\mathrm{Li} / \mathrm{S}$ battery showed the initial discharge capacity of $1222 \mathrm{mAh} \cdot \mathrm{g}^{-1}$ for the sulfur electrode with PPy as matrix and the remaining capacity of $570 \mathrm{mAh} \cdot \mathrm{g}^{-1}$ after $20^{\text {th }}$ cycles. With these results, it was concluded that good electrochemical properties were found when PPy nano-wire was used in rechargeable lithium batteries.

A tubular polypyrrole (T-PPy) fibre as another type of conductive matrixes was introduced by Liang et al. [39]. During the co-heating process, which was applied in this paper, the capillary force allowed the sulfur to penetrate into the T-PPy fibre matrix. They have found that the electrochemical behaviour of the composite mostly depended on the location and the content of sulfur. The result showed that the reversible capacity of $650 \mathrm{mAh} \cdot \mathrm{g}^{-1}$ was maintained for over 80 cycles for the S/T-PPy composite with $30 \mathrm{wt} \%$ sulfur and initial discharge capacity was $1151.7 \mathrm{mAh} \cdot \mathrm{g}^{-1}$. Therefore, the enhanced conductivity, the favourable distribution of the nano-sized sulfur in the T-PPy and the stable retention of polysulphides lead to the improvement of the cycling stability of the sulfur based electrode.

\subsection{Effect of Binder}

The uniform combination of active sulfur and conductive carbon is very important for a high performance sulfur cathode. Among the components in the sulfur cathode, the binder plays an important role in improving cell performance, especially in regards to the cycle life. A high performance binder should have high adhesion ability for the electrode materials to the current collector, as well as the ability to form a good electric network between the active material and conductive carbon, to facilitate the electron transport as well as the diffusion of the lithium ion [40].

Based all the studies of lithium-sulfur battery system, PEO and PVDF are the most commonly used binder, but both of them still have revealed some problems [40]. The PEO-based sulfur cathode usually presents poor adhesion properties [41, 42] and low ionic conductivity at low temperature [43]. The PVDF binder is readily dissolved in 
the organic electrolytes, especially at elevated temperatures, resulting in an increase in the interfacial resistance [44]. Besides that, the PVDF binder must be dispersed in some high boiling solvent such as N-methyl-2-pyrrolidone (NMP), which tends to be difficult to vaporize, so the drying process of the cathode might lead to the loss of active sulfur at temperatures higher than $80{ }^{\circ} \mathrm{C}$ under vacuum [40].

Sun et al. developed a water-soluble gelatin macromolecule was adopted as the binder in the fabrication of the sulfur cathode in lithium-sulfur batteries [40]. This gelatin was formed by the covalent linkage of several amino acids into a stable peptide, where the sequence of the peptide chain was determined by the protocol used in its production. The structure and electrochemical performance of the two types of sulfur cathodes, with gelatin and poly (ethylene oxide) (PEO) as binders, respectively, were compared in $1 \mathrm{M}$ $\mathrm{LiClO}_{4} \quad \mathrm{DME} / \mathrm{DOL}(\mathrm{V} / \mathrm{V}=1 / 1)$ electrolyte. The results showed that the gelatin binder had multifunctional effects on the sulfur cathode: it not only functioned as a highly adhesive agent and an effective dispersion agent for the cathode materials, but also an electrochemically stable binder. The gelatin binder-sulfur cathode achieved a high initial capacity of $1132 \mathrm{mAh} \cdot \mathrm{g}^{-1}$, and remained at a reversible capacity of $408 \mathrm{mAh} \cdot \mathrm{g}^{-1}$ after 50 cycles, all of which were better than with the PEO binder-sulfur cathode under the same conditions.

Wu et al. studied Ball milling in combination with heat treatment was used to prepare sulfur-based composite cathode materials incorporating multi-walled carbon nanotubes (MCNTs). The effect of MCNT content and binder type on the capacity, cyclability and self-discharge behavior of a sulfur-based cathode were systematically investigated ${ }^{[45]}$. Results showed that the appropriate amount of MCNTs was 5\%-8\% (w, mass fraction) and the use of $\beta$ cyclodextrin as a water-soluble binder resulted in the best electrochemical performance. When the Li-S battery was half charged at room temperature, there was almost no selfdischarge during storage for 30 days. The charging capacity was $687.7 \mathrm{mAh} \cdot \mathrm{g}^{-1}$ during the $1 \mathrm{st}$ cycle and $623.8 \mathrm{mAh} \cdot \mathrm{g}^{-1}$ during the 100th cycle for the cathode at a current rate of $0.1 \mathrm{C}$. Therefore, $90.7 \%$ of the capacity was retained.

\section{EFFECT OF ANODE AND MODIFICATION}

The use of elemental lithium as the anode in lithiumsulfur batteries remains a major problem due to safety concerns arising from the formation of lithium dendrites during cycling, which can penetrate the separator and lead to thermal runaway [46]. One way to avoid this safety issue in the lithium/sulfur system is to use a high-capacity anode material other than elemental lithium while replacing sulfur in the cathode with its lithiated counterpart, lithium sulfide $\left(\mathrm{Li}_{2} \mathrm{~S}\right)$ [46].

The electrochemical behavior of $\mathrm{Li}_{2} \mathrm{~S}-\mathrm{C}$ cathode in combination with a tin-carbon composite and a gel-type polymer electrolyte was investigated [47]. This new Sn$\mathrm{C} / \mathrm{Li}_{2} \mathrm{~S}$ polymer battery operates with a capacity of 600 $\mathrm{mAh} \cdot \mathrm{g}^{-1}$ and the energy density of $1200 \mathrm{Whkg}^{-1}$. XRD analysis performed in situ in a lithium cell shows that lithium sulphide can be converted into sulfur during charge and reconverted back into sulfide during the following discharge process. $\mathrm{Li}_{2} \mathrm{~S}-\mathrm{C}$ composite can be used as cathode for the development of novel types of rechargeable lithium-ion sulfur batteries where the reactive and unsafe lithium metal anode is replaced by a reliable, high capacity tin-carbon composite and the unstable organic electrolyte solution is replaced by a composite gel polymer membrane that is safe, highly conductive and able to control dendrite growth across the cell [47].

A novel nanostructured rechargeable battery consisting of a $\mathrm{Li}_{2} \mathrm{~S} / \mathrm{CMK}-3$ mesoporous carbon cathode and a silicon nanowire anode was prepared to replace sulfur in the cathode [46]. An initial discharge specific energy of $630 \mathrm{Whkg}^{-1}$ based on the mass of the active electrode materials was realized Silicon nanowire anodes are demonstrated to be ideal for this battery system due to their high capacity, low reaction potential, and moderate cycle life. This new battery system avoids the intrinsic safety issues associated with the use of lithium metal in previous lithium/sulfur batteries [46].

\section{EFFECT OF ELECTROLYTE}

\subsection{New Electrolyte}

The sulfur, which has a crown-like ring structure, forms various lithium polysulfides as a result of the reduction, which are generally soluble in the electrolyte phase [48-50]. For the successful operation of a lithium-sulfur battery, the electrolyte should satisfy many requirements, i.e. high ionic conductivity, good polysulfide solubility, low viscosity, electrochemical stability, chemical stability toward lithium, and safety ${ }^{[48]}$. Different types of new electrolytes such as polymer electrolyte and ceramic electrolyte have been evaluated for their suitability in $\mathrm{Li} / \mathrm{S}$ cells.

Polymer electrolytes can be introduced to restrain the dissolution of polysulfides into the electrolyte. Polymer electrolytes explored for this purpose are commonly complexes of a lithium salt (LiX) with a high-molecularweight polymer such as polyethylene oxide (PEO). But PEO tends to crystallize below $60^{\circ} \mathrm{C}$, whereas fast ion transport is a characteristic of the amorphous phase. So the conductivity of PEO-LiX electrolytes reaches practically useful values (of about $10^{-4} \mathrm{~S} \mathrm{~cm}^{-1}$ ) only at temperatures of $60-80^{\circ} \mathrm{C}$ [51]. Some researchers have been tried to solve the problems with the use of nano-scale ceramic filler such as $\mathrm{Al}_{2} \mathrm{O}_{3}, \mathrm{SiO}_{2}$, and $\mathrm{TiO}_{2}$ in PEO based polymer electrolyte [51-53]. The additive improved the conductivity of PEO base electrolytes as well as their interfacial resistance between the electrolyte and the lithium electrode.

Croce et al. [51] prepared the conductivities of around $10^{-4} \mathrm{~S} \mathrm{~cm}^{-1}$ at $50^{\circ} \mathrm{C}$ and $10^{-5} \mathrm{~S} \mathrm{~cm}^{-1}$ at $30^{\circ} \mathrm{C}$ in a PEO- $\mathrm{LiClO}_{4}$ mixture containing powders of $\mathrm{TiO}_{2}$ and $\mathrm{Al}_{2} \mathrm{O}_{3}$ with particle sizes of 5.8-13 nm. Another approach is to decrease the crystallinity of the polymer in order to improve the polymer chain mobility [54].

Smith et al. have reported that high energy mechanical milling conducted at ambient and cryogenic temperature can decrease the molecular weight and glass transition temperature in poly(methylmethacrylate) (PMMA) or poly (ethylene propylene) (PEP) [55].

Jeong et al. [56] found that ball milled PEO-base polymer electrolytes with ceramic filler displayed higher ionic conductivity and interfacial stability than that without ceramic fillers. PEO-LiBF 4 polymer electrolyte with nano- 
$\mathrm{Al}_{2} \mathrm{O}_{3}$ prepared by ball milling for was further investigated in the discharge process of lithium/sulfur battery. The cycle performance and initial discharge capacity of $\mathrm{Li} /(\mathrm{PEO})_{6} \mathrm{LiBF}_{4}$ /S cell was remarkably improved by the addition of $\mathrm{Al}_{2} \mathrm{O}_{3}$ [54]. The initial discharge capacity of lithium sulfur cell using BCPE was $1670 \mathrm{mAh} \cdot \mathrm{g}^{-1}$, which was approximately equal to the theoretical capacity. These improvements of cell performance were attributed to the stability of $2.1 \mathrm{~V}$ plateau, thus $\mathrm{Al}_{2} \mathrm{O}_{3}$ filler stabilized formation of $\mathrm{Li}_{2} \mathrm{~S}$ and improved utilization of sulfur.

Wang et al. [57] prepared PVDF-HFP gel electrolyte used in rechargeable lithium battery based on the sulfur/active carbon cathode, which showed good cyclability. And elemental sulfur was embedded and trapped in nano-and micro-pores of active carbon. The reversible capacity of the composite was about 440 $\mathrm{mAh} \cdot \mathrm{g}^{-1}$ and the utilization of sulfur during cycling approaches $90 \%$.

PVDF-TG-LiX polymer electrolytes comprised of polyvinylidene fluoride-hexafluoropropylene (PVDF-HFP) copolymer, tetra (ethylene glycol) dimethyl ether as plasticizer, $\mathrm{LiCF}_{3} \mathrm{SO}_{3}, \mathrm{LiBF}_{4}$ and $\mathrm{LiPF}_{6}$ as lithium salt and acetone as solvent was prepared by solvent casting of slurry that mixed PVDF-HFP copolymer with acetone and salt using a ballmilling technique [58]. The PVDF-TG-LiPF 6 polymer electrolytes prepared by ball-milling, for, $12 \mathrm{~h}$, in particular, resulted in a maximum value in the ionic conductivity, which was $4.99 \times 10^{-4} \mathrm{~S} \mathrm{~cm}^{-1}$ at room temperature. The melting temperature of crystalline PVDF decreased due to the decrease of crystallinity by scission of the polymer chain during ball milling. This gel polymer electrolyte was employed into $\mathrm{Li} / \mathrm{S}$ battery based on the $\mathrm{S}$ cathode and $\mathrm{Li}$ anode. The initial discharge capacity can reach to $765 \mathrm{mAh \cdot g}{ }^{-1}$ at the rate of 0.14 $\mathrm{mA} \mathrm{cm}{ }^{-2}$.

All solid-state batteries using sulfide solid electrolyte (SE) are of great advantage than the batteries of liquid electrolytes, because solid-solid contact causes no dissolution problem and the same constituent components make the SE/electrode interface easier [59]. Thio-LISICON $\left(\mathrm{Li}_{3.25} \mathrm{Ge}_{0.25} \mathrm{P}_{0.75} \mathrm{~S}_{4}\right)$ synthesized by solid-state reaction was used as a solid electrolyte [60]. Electrode framework was investigated using various type of carbons; meso-porous carbons with two and three-dimensional structures, CMK-3, and carbon replica [61]. The all solid-state lithium battery with the composite electrode of sulfur and CMK-3 showed a reversible capacity of 1000 $\mathrm{mAh} \cdot \mathrm{g}^{-1}$ with significant degradation of charge-discharge capacities after several cycles. The degradation of the chargedischarge characteristics was due the sulfur existed outside of the meso-pore of the carbon framework structure [59].

\subsection{Additive on Electrolyte}

For the liquid electrolyte, most often, a single organic solvent does not meet all the requirements of an electrolyte in a $\mathrm{Li} / \mathrm{S}$ cell and optimization based on a mixture of solvents.

The effect of incorporating varying amounts of toluene additive in $1 \mathrm{M} \mathrm{LiCF}_{3} \mathrm{SO}_{3}$ in tetra (ethylene glycol) dimethyl ether (TEGDME) liquid electrolyte on the electrochemical performance of $\mathrm{Li} / \mathrm{S}$ cell at room temperature was studied [62]. It was found that the addition of toluene in low amounts was an effective means to enhance the electrochemical performance of $1 \mathrm{M} \mathrm{LiCF}_{3} \mathrm{SO}_{3}$ in TEGDME electrolyte in $\mathrm{Li} / \mathrm{S}$ cells at room temperature. Electrolytes with toluene have higher redox currents resulting from increased ion mobility and ionic conductivity. Toluene addition enhanced initial discharge capacity; a maximum of $750 \mathrm{mAh} \cdot \mathrm{g}^{-1}$ ( $45 \%$ of the theoretical specific capacity of sulfur) was obtained with $5 \%$ of toluene, which was 1.8 times that of the cell without toluene. The electrolyte with $5 \%$ toluene exhibited a stable cycle performance with the highest discharge capacity and charge-discharge efficiency. AC impedance analyses of $\mathrm{Li} / \mathrm{S}$ cells with the electrolytes showed that toluene addition resulted in a lower initial interfacial resistance and a fast stabilization of electrode/electrolyte interfaces in the cell [62].

Tetra ethylene glycol dimethylether (TEGDME) electrolyte was used to improve the performance of $\mathrm{Li} / \mathrm{S}$ batteries [63]. A Li-S cell with stainless-steel currentcollectors exhibited severe self-discharge behaviour. After 30 days of storage, the open-circuit voltage (OCV) dropped from 2.5 to $2.2 \mathrm{~V}$ and the discharge capacity decreased to $72 \%$ of the original capacity. With the analysis of the selfdischarged sulfur electrodes by SEM, XRD, and DSC, it was concluded that polysulfides are formed from the lithium and sulfur ions, and are which are linked to the corrosion of the stainless-steel current-collector. Stainless steel is not an appropriate material for use as the current-collector for the sulfur electrode in the Li-S cell. The self-discharge rate of the Li-S cell can be decreased by using a gold-coated current-collector, which can provide corrosion resistance.

These studies from Aurbach et al. showed the impact of the presence of $\mathrm{LiNO}_{3}$ in solution on the surface chemistry of $\mathrm{Li}$ electrodes: Its direct reduction to form surface $\mathrm{Li}_{\mathrm{x}} \mathrm{NO}_{\mathrm{y}}$ species and the oxidation of sulfur species to form various $\mathrm{Li}_{\mathrm{x}} \mathrm{SO}_{\mathrm{y}}$ surface moieties [64]. This impact explains the positive effect of $\mathrm{LiNO}_{3}$ in preventing the shuttle mechanism that avoids full charging of sulfur electrodes in Li-S cells: The enhancement of $\mathrm{Li}$ passivation, which diminishes the possible reduction in polysulfide species in solutions by the reactive lithium electrodes.

\section{CONCLUSION}

Li/S battery provides us much hope, but also many challenges. In general, the main problem in $\mathrm{Li} / \mathrm{S}$ battery is having poor cyclic ability, which is mainly caused by polysulfides dissolving into the electrolyte. To solve this problem, together with advances of the anode and the electrolyte, the materials, such as active carbon, can be chosen with sulfur as a composite cathode in the $\mathrm{Li} / \mathrm{S}$ battery to contain the most polysulfides. Besides that, certain materials with high conductivity that cover the surface of the sulfur particles encourage a long cycle life. Promisng results have been achieved by modifying the cathode in the $\mathrm{Li} / \mathrm{S}$ battery. Evenly distributing sulfur in the composite cathode, enhancing the conductivity of the composite cathode, and stabilizing the retention of polysulfides, along with the use of a non-metal lithium metal will lead to the employment of sulfur based cathode batteries in the commercial world

\section{REFERENCES}

[1] Zhang Y, Wang LZ, Zhang A et al. Novel $\mathrm{V}_{2} \mathrm{O}_{5} / \mathrm{S}$ composite cathode material for the advanced secondary lithium batteries. Solid State Ionics 2010; 181: 835-8.

[2] Zhang Y, Zhang AQ, Gui YH et al. Application of biphenyl additive in electrolyte for liquid state Al-plastic film lithium-ion batteries. J Power Sources 2008; 185: 492-500. 
[3] Xiang JF, Chang CX, Zhang F et al. Effects of Mg doping on the electrochemical properties of $\mathrm{LiNi}_{0.8} \mathrm{Co}_{0.2} \mathrm{O}_{2}$ cathode material. $\mathrm{J}$ Alloys Compd 2009; 475: 483-7.

[4] Chen XJ, Cao GS, Zhao XB et al. Electrochemical performance of $\mathrm{LiFe}_{1-\mathrm{x}} \mathrm{V}_{\mathrm{x}} \mathrm{PO}_{4} /$ carbon composites prepared by solid-state reaction. $\mathrm{J}$ Alloys Compd 2008; 463: 385-9.

[5] Kolosnitsyn VS, Karaseva EV. Lithium-Sulfur Batteries: Problems and Solutions. Russ J Electrochem 2008; 44: 506-9.

[6] Besenhard JO. Handbook of Battery Materials. Wiley: New York; 1998.

[7] Jin B, Kim JU, Gu HB. Electrochemical properties of lithiumsulfur batteries. J Power Sources 2003; 117: 148-52.

[8] Kobayashi T, Imade Y, Shishihara D et al. All solid-state battery with sulfur electrode and thio-LISICON electrolyte. J Power Sources 2008; 182: 621-5.

[9] Ji XL, Lee KT, Nazar LF. A highly ordered nanostructured carbonsulfur cathode for lithium-sulfur batteries. Nat Mater 2009; 8: 5006.

[10] Song MS, Han SC, Kim HS et al. Effects of nano-sized adsorbing material on electrochemical properties of sulfur cathodes for $\mathrm{Li} / \mathrm{S}$ secondary batteries. J Electrochem Soc 2004; 151: A791-5.

[11] Yamin H, Gorenshtein A, Penciner J et al. Lithium Sulfur Battery Oxidation/Reduction Mechanisms of Polysulfides in THF Solutions. J Electrochem Soc 1988; 135: 1045-8.

[12] Yamin H, Penciner J, Gorenshtain A et al. The electrochemical behavior of polysulfides in tetrahydrofuran. J Power Sources 1985; 14: $129-34$

[13] Marmorstein D, Yu TH, Striebel KA et al. Electrochemical performance of lithium/sulfur cells with three different polymer electrolytes. J Power Sources 2000; 89: 219-26.

[14] Degott P, Ph.D. Thesis, l'Institut National Polytechnique de Grenoble, France; 1986.

[15] Chu MY. Rechargeable positive electrode. US5523179, June 4, 1996.

[16] Eichinger G, Besenhard J. High energy density lithium cells. Part II. Cathodes and complete cells. J Electroanal Chem 1976; 72: 131.

[17] Murphy DW, Carides JN. Low Voltage Behavior of Lithium/Metal Dichalcogenide Topochemical Cells. J Electrochem Soc 1979; 126: $349-51$.

[18] Ho CB, Ph.D. Thesis, Korea Advance Institute of Science and Technology; 2001.

[19] Nimon ES, Sukeshini M, Visco SJ: The $11^{\text {th }}$ International Meeting on Lithium Batteries; June 2002; Monterey, California, US; 2002.

[20] Wang JL, Yang J, Xie JY et al. Sulfur-carbon nano-composite as cathode for rechargeable lithium battery based on gel electrolyte. Electrochem Commun 2002; 4: 499-502.

[21] Bonhote P, Dias A, Papageorgiou N et al. Hydrophobic, highly conductive ambienttemperature molten salts. Inorg Chem 1996; 35:1168-78.

[22] Liang CD, Dudney NJ, Howe JY. Hierarchically Structured Sulfur/Carbon Nanocomposite Material for High-Energy Lithium Battery. Chem Mater 2009; 21: 4724-30.

[23] Wang XQ, Liang CD, Dai S. Facile synthesis of ordered mesoporous carbons with high thermal stability by self-assembly of resorcinol-formaldehyde and block copolymers under highly acidic conditions. Langmuir 2008; 24: 7500-5.

[24] Liang CD, Dai S. Synthesis of mesoporous carbon materials via enhanced hydrogen-bonding interaction. J Am Chem Soc 2006; 128: 5316-7.

[25] Liang CD, Hong KL, Guiochon GA et al. Synthesis of a large-scale highly ordered porous carbon film by self-assembly of block copolymers. Chem Int Ed 2004; 43: 5785-9.

[26] Steinhart M, Liang CD, Lynn GW et al. Direct Synthesis of Mesoporous Carbon Microwires and Nanowires.

Chem Mater 2007; 19: 2383-5.

[27] Wang J, Chew SY, Zhao ZW et al. Sulfur-mesoporous carbon composites in conjunction with a novel ionic liquid electrolyte for lithium rechargeable batteries. Carbon 2008; 46: 229-35.

[28] Wang JL, Yang J, Wan CR et al. Sulfur composite cathode materials for rechargeable Lithium batteries. Adv Funct Mater 2003; 13: 487-92.

[29] Wei W, Wang JL, Zhou LJ et al. CNT enhanced sulfur composite cathode material for high rate lithium battery. Electrochem. Commun. (2011), doi:10.1016/j.elecom.2011.02.001
[30] Zhang SC, Zhang L, Wang WK et al. A Novel cathode material based on polyaniline used for lithium/sulfur secondary battery. Synth Met 2010; 160: 2041-4.

[31] Ma P, Zhang BH, Xu YH et al. Study on improving properties of elemental sulfur cathode materials by coating PANi. Mod Chem Ind 2007; 27: 30-3.

[32] Henriksen GL, Kaun T, Jansen A et al. The Electrochemical Society Proceedings Series. Pennington: New Jersey; 1998.

[33] Zhang Y, Wu XB, Feng $\mathrm{H}$ et al. Effect of nanosized $\mathrm{Mg}_{0.8} \mathrm{Cu}_{0.2} \mathrm{O}$ on electrochemical properties of $\mathrm{Li} / \mathrm{S}$ rechargeable batteries. Int $\mathrm{J}$ Hydrogen Energy 2009; 34:1556-9.

[34] Han SC, Song MS, Lee H et al. Effect of multiwalled carbon nanotubes on electrochemical properties of Lithium/Sulfur rechargeable batteries. J Electrochem Soc 2003; 150: A889-93.

[35] Choi YJ, Kim KW, Ahn HJ et al. Improvement of cycle property of sulfur electrode for lithium/sulfur battery. J Alloys Compd 2008; 449: 313-6.

[36] Wang J, Chen J, Konstantinov K et al. Sulfur-polypyrrole composite positive electrode materials for rechargeable lithium batteries. Electrochim Acta 2006; 51: 4634-8.

[37] Zhang XT, Zhang J, Song WH et al. Controllable Synthesis of Conducting Polypyrrole Nanostructures. J Phys Chem B 2006; 110: 1158-65.

[38] Sun MM, Zhang SC, Jiang T et al. Nano-wire networks of sulfurpolypyrrole composite cathode materials for rechargeable lithium batteries. Electrochem Commun 2008; 10: 1819-22.

[39] Liang X, Liu Y, Wen ZY et al. A nano-structured and highly ordered polypyrrole-sulfur cathode for lithium-sulfur batteries. J Power Sources (2010), doi:10.1016/j.jpowsour.2010.11.132

[40] Sun J, Huang YQ, Wang WK et al. Application of gelatin as a binder for the sulfur cathode in lithium-sulfur batteries. Electrochimica Acta 2008; 53: 7084-8.

[41] Cheon SE, Cho JH, Ko KS et al. Structural factors of sulfur cathodes with poly (ethylene oxide) binder for performance of rechargeable lithium sulfur batteries. J Electrochem Soc 2002; 149: A1437-41.

[42] Cheon SE, Ko KS, Cho JH et al. Rechargeable lithium sulfur battery II. Rate capability and cycle characteristics. J Electrochem Soc 2003; 150: A800-5.

[43] Croce F, Persi L, Ronci $F$ et al. Nanocomposite polymer electrolytes and their impact on the lithium battery technology. Solid State Ionics 2000; 135: 47-52.

[44] Zhang SS, Jow TR. Study of poly (acrylonitrile-methyl methacrylate) as binder for graphite anode and $\mathrm{LiMn}_{2} \mathrm{O}_{4}$ cathode of Li-ion batteries. J Power Sources 2002; 109: 422-6.

[45] Wu YL, Yang J, Wang JL et al. Composite cathode structure and binder for high performance lithium-sulfur battery. Acta PhysicoChimica Sinica 2010; 26: 283-90.

[46] Yang Y, McDowell MT, Jackson A et al, New nanostructured $\mathrm{Li}_{2} \mathrm{~S} /$ Silicon rechargeable battery with high specific energy. Nano Lett 2010; 10: 1486-91.

[47] Hassoun J, Sun YK, Scrosati B. Rechargeable lithium sulfide electrode for a polymer tin/sulfur lithium-ion battery. J Power Sources 2011; 196: 343-8.

[48] Chang DR, Lee SH, Kim SW et al. Binary electrolyte based on tetra(ethylene glycol) dimethyl ether and 1,3-dioxolane for lithiumsulfur battery. J Power Sources 2002; 112: 452-60.

[49] Rauh RD, Shuker FS, Marston JM et al. Formation of lithium polysulfides in aprotic media. J Inorg Nucl Chem 1977; 39: 1761-6.

[50] Paris J, Plichon V. Electrochemical reduction of sulfur in dimethylacetamide. Electrochem Acta 1981; 26: 1823-9.

[51] Croce F, Appetecchi GB, Persi L et al. Nanocomposite polymer electrolytes for lithium batteries. Nature 1998; 394: 456-8.

[52] Croce F, Curini R, Martinelli A et al. Physical and chemical properties of nanocomposite polymer electrolytes. J Phys Chem B 1999; 103: 10632-8.

[53] Krawice W, Scanlon Jr. LG, Fellner JP et al. Polymer nanocomposites: a new strategy for synthesizing solid electrolytes for rechargeable lithium batteries. J Power Sources 1995; 54: 3105.

[54] Jeong SS, Lim YT, Choi YJ et al. Electrochemical properties of lithium sulfur cells using PEO polymer electrolytes prepared under three different mixing conditions. J Power Sources 2007; 174: 74550 . 
[55] Smith AP, Shay JS, Spontak RJ et al. High-energy mechanical milling of poly (methyl methacrylate), polyisoprene and poly (ethylene-alt-propylene). Polymer 2000; 41: 6271-83.

[56] Jeong SS, Lim YT, Jung BS et al. Electrochemical characteristics of $\mathrm{Li} / \mathrm{S}$ secondary battery with $(\mathrm{PEO})_{6} \mathrm{LiBF}_{4}-\mathrm{Al}_{2} \mathrm{O}_{3}$ composite polymer electrolyte prepared by ball milling. Mater Sci Forum 2005; 486-487: 594-7.

[57] Wang JL, Yang J, Xie JY et al. Sulfur-carbon nano-composite as cathode for rechargeable lithium battery based on gel electrolyte. Electrochem Commun 2002; 4: 499-502.

[58] Shin JH, Jung SS, Kim KW et al. Preparation and characterization of plasticized polymer electrolytes based on the PVdF-HFP copolymer for lithium/sulfur battery. J Material Science: Materials in Electronics 2002; 13: 727-33.

[59] Kanno R, Nagao M, Imade Y et al. All solid-state lithium-sulfur battery using mesosized electrode structure and thio-LISICON. $15^{\text {th }}$ International meeting on Lithium Batteries. Montreal; 2010.
[60] Kanno R, Murayama M. Lithium ionic conductor thio-LISICON: The $\mathrm{Li}_{2} \mathrm{~S}-\mathrm{GeS}_{2}-\mathrm{P}_{2} \mathrm{~S}_{5}$ System. J Electrochem Soc 2001; 148: A7426.

[61] Yokoi T, Iwama M, Watanabe R et al. Synthesis of well-ordered nanospheres with uniform mesopores assisted by basic amino acids. Proceedings of the $15^{\text {th }}$ International Zeolite Conference 2007; 170: 1774-80.

[62] Choi JW, Cheruvally G, Kim DS et al. Rechargeable lithium/sulfur battery with liquid electrolytes containing toluene as additive. J Power Sources 2008; 183: 441-5.

[63] Ryu HS, Ahn HJ, Kim KW et al. Self-discharge characteristics of lithium/sulfur batteries using TEGDME liquid electrolyte. Electrochimica Acta 2006; 52: 1563-6.

[64] Aurbach D, Pollak E, Elazari R et al. On the surface chemical aspects of very high energy density, rechargeable Li-Sulfur batteries. J Electrochem Soc 2009; 156: A694-702. 